\title{
Numerical Simulation Analysis of Slope Instability and Failure of Limestone Mine in Weibei
}

\author{
Kuiming Liu $\mathbb{D}^{2,3}$ Hui Li, ${ }^{2,3}$ Shihui Pang, ${ }^{2,3}$ Meng Mi $\mathbb{D}^{2,3}{ }^{2,3}$ Janping Chen, ${ }^{1}$ and Kui Sun ${ }^{1}$ \\ ${ }^{1}$ Key Laboratory of Mine Geological Hazards Mechanism and Control, Xian 710054, China \\ ${ }^{2}$ State Key Laboratory for Geomechanics and Deep Underground Engineering, \\ China University of Mining and Technology (Beijing), Beijing 100083, China \\ ${ }^{3}$ School of Mechanics and Civil Engineering, China University of Mining and Technology (Beijing), Beijing 100083, China \\ Correspondence should be addressed to Meng Mi; 294704212@qq.com
}

Received 4 May 2021; Accepted 16 September 2021; Published 21 October 2021

Academic Editor: Gan Feng

Copyright (c) 2021 Kuiming Liu et al. This is an open access article distributed under the Creative Commons Attribution License, which permits unrestricted use, distribution, and reproduction in any medium, provided the original work is properly cited.

\begin{abstract}
Weibei area is the largest limestone resource area in Shaanxi Province, which is an important boundary to distinguish the climate difference between the south and the north of China, and also a significant ecological safety protection barrier in the northwest of China. The complex geological environment and harsh environment make the mining area have serious geological disaster hidden danger. Based on the site engineering geological data of typical limestone quarry slope in Weibei, this paper constructs a threedimensional geological model, uses FLAC3D software to simulate excavation, and analyzes the stress and strain law of the quarry slope. SlopeLE software was used to analyze the safety factor of slope stability and the potential slip surface before and after taking reinforcement measures. The results show the following: (1) Limestone is the main rock component of the mine, followed by mudstone. The joint and fissure are developed, the rock mass is broken, and the hidden danger of engineering geological disaster is high. (2) There is a sliding trend in both sides during excavation, and the maximum vertical displacement is $2.1 \mathrm{~cm}$. (3) If the slope is reinforced according to the design scheme, the slope stability safety factor will be increased from 1.062 to 1.203 in a stable state, which greatly improves the stability of the slope and provides a guarantee for human and financial resources.
\end{abstract}

\section{Introduction}

Weibei area in Shaanxi Province is the dividing line of climate between the north and south of China and an important ecological security barrier. It has many functions, such as regulating climate, conserving soil and water, and maintaining biodiversity. The Party Central Committee and the State Council attach great importance to the mine geological environment protection and management planning in Weibei area. With the continuous extension of openpit mining, the stability of open-pit slope is more and more concerned by mining enterprises, and the potential safety problems caused by slope instability are more and more prominent [1]. Moreover, the geological environment of Weibei limestone mining area is complex, which is affected by the external environment. There are serious geological disasters in the mining area. Especially in recent years, the mining area has developed rapidly, but there is a lack of long-term monitoring and control of the geological environment in the mining area, so the geological environment in the mining area has deteriorated sharply, and geological disasters occur frequently, which seriously threatens the safety of people in the mining area and the development of mining resources [2-4].

The numerical calculation method [5-20] is widely used in geotechnical engineering. It can present the realistic slope and its geological environment, strata, and lithology and whether there is joint surface in the computer software and analyze the failure mechanism according to the results of simulation calculation. At present, a series of numerical methods have been developed for different types of sliding bodies, such as finite difference method (FDM) and finite volume method (FVM). In terms of model establishment and control theory, such as discrete element (DEM), 
discontinuous deformation (DDA), Dan, smoothed particle flow $(\mathrm{SPH})$, particle flow program (PFC), and tsunami ball, some numerical simulation software came into being, such as FLAC, UDEC, PFC, 3DEC, and geo slope. Among them, FLAC3D numerical simulation software [21-28] is good at analyzing large deformation problems in geotechnical engineering, and it adopts display calculation method, which can ensure that better calculation results can be obtained even without convergence of calculation.

Zhu et al. [29] put forward a constitutive model that can reflect the working principle of yielding anchor cable and successfully realized the numerical simulation method of yielding anchor cable slope reinforcement by combining FLAC3D software and FORTRAN programming language. Gao et al. [30] used the discrete element method to study the deformation and failure characteristics of a total of 270 slope models under different working conditions. Wang et al. [31] proposed that the most effective methods for studying the influence of rainfall factors on slope stability are indoor and outdoor experiments and numerical simulation methods. Tan et al. [32] used the discrete element method to carry out the full-time dynamic analysis of the slope rock mass and discussed the dynamic response law and stability of the slope rock mass under the action of earthquake. Yang et al. [33] used numerical simulation to determine the critical length of instability failure during excavation of a multilayer soft interbedded rock slope. Liu et al. [34] used discrete element UDEC software to simulate the antidipping soft and hard rock mass interbedded slope and systematically studied the deformation and failure mechanism of its seismic response. Chen et al. [35] used FLAC3D to establish a numerical model of a large-scale open-air slope, and through three-dimensional numerical simulation revealed the mechanical environment of a large-scale open-air slope, and discussed the movement and deformation, stress distribution, and failure mechanism of surrounding rock. Gu et al. [36] proposed that three-dimensional numerical simulation is more targeted for the deformation analysis of irregular section slope, and the influence of section morphology change on slope deformation can be considered. The calculated results are highly consistent with the actual deformation state.

FLAC3D can very accurately simulate the flow and plastic failure of materials and can be used for foundation design and slope stability. It has great advantages in solving geotechnical engineering problems and has been recognized by many scholars $[37,38]$. Therefore, this paper will use FLAC3D numerical simulation method to carry out numerical simulation analysis on the slope of limestone quarry in Weibei area to reproduce and analyze the specific process of slope deformation and failure.

\section{Regional Geological Features}

2.1. Physical Geographic Features. Xianyang City is located in the south of Taiao of Shaanxi-Gansu-Ningxia. From the fold fault band of Shaanxi-Gansu-Ningxia sag to the north and south of the two III structural units, the structure changes from strong to weak, from complex to simple, and JingheLishan fault basically crosses Xianyang City. Baoji City is located at the western end of the Weihe Fault Depression. The east-west and northwest-trending fault structures are extremely developed. The Guguan-Yangpingzhen fault runs through Baoji and develops northward, and the LongxianMazhao fault is located between Xianyang and Baoji, developing in the northeast direction. The distribution of structural faults in Weibei area is shown in Figure 1. Groundwater in this mine area mainly includes quaternary unconsolidated pore, fissure water, bedrock fissure water, and carbonate pore water, and its recharge is mainly by atmospheric rainfall.

2.2. Mine Geological Environmental Problems. In the dual role of nature, man-made behaviors often make mine geological disasters occur frequently, which will make the mine geological ecological environment deteriorate and cause economic losses. At the same time, it will greatly threaten the survival and development of human beings and also endanger the mineral resources on which human beings depend for survival and development. At present, there are many kinds of mines in China, with a wide distribution area, which has a great impact on the national development and people's life. In recent years, the mine hazards in Weibei area have also shown an upward trend. The goaf collapse, landslide, collapse, soil erosion, debris flow, and other geological disasters occur frequently, which has become the most important types of hazards. There are 9 mine geological disasters, including 3 small- and medium-sized landslides, 6 collapses, and hidden dangers. Small- and medium-sized geological disasters are the main types of geological disasters in Weibei area, accounting for $72 \%$ of the total, while largeand medium-sized geological disasters account for $28 \%$. The open-pit limestone mining process not only caused great damage to the landscape, but also formed a large area of high steep rock faces, pits, vegetation stripping, and exposed rocks, full of greens, and was extremely inconsistent with the surrounding emerald-covered landforms. Moreover, according to statistics, mine waste in the Weibei area currently has a total of $350 \times 10^{4} \mathrm{t}$, all of which are waste rock slag, with an annual output of $30 \times 10^{4} \mathrm{t}$ and an annual utilization of $10 \times 10^{4} \mathrm{t}$ (Figure 2).

\section{FLAC3D Numerical Simulation Analysis of Limestone Mine Slope Instability Caused by Excavation}

3.1. Introduction to FLAC3D. With the continuous progress of science and technology, the numerical simulation method has been applied to geotechnical engineering by more and more experts and scholars. It can simulate and analyze the failure mechanism of real slope and its geological environment, stratum, lithology, and joint surface in computer software. FLAC3D is a fast three-dimensional Lagrangian analysis program, which uses explicit Lagrangian algorithm and hybrid discrete partition technology to simulate the three-dimensional mechanical properties of geotechnical materials. The program can simulate the failure and plastic flow of the geological body under the strength and yield limit, especially suitable for analyzing the gradual failure and 


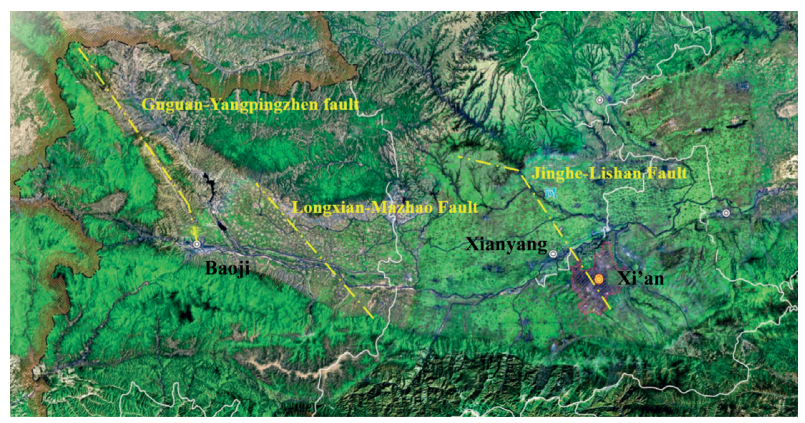

FIgURE 1: Geological structure characteristics in Weibei area.

instability process of slope and simulating the large deformation of slope. In summary, the main calculation process of FLAC3D includes repetitive processes such as modeling, calculation solution, result review, and recommissioning (Figure 3), which can monitor the change process of a point's displacement, velocity, acceleration, stress, and other parameters.

The choice of constitutive model is an important step that affects the accuracy of numerical simulation. The FLAC3D software contains 12 constitutive models, including the Mohr-Coulomb plastic model, which are suitable for the mechanical properties of different engineering materials. The Mohr-Coulomb model is one of the most widely used models in slope stability analysis. It has the advantages of less requirements for relevant material parameters and easy access. Therefore, the Mohr-Coulomb constitutive model is used to simulate the mechanical properties and progressive failure process of the rock-soil mass of the bottom slope.

The stress on each surface of the model and the displacement constraints in each direction are important factors that affect the final calculation results of the numerical model. According to the different purposes of different models, displacement constraints in different directions are added. For the numerical simulation model, the specific boundary displacement constraint expression is as follows:

(1) Apply horizontal displacement constraints on the left, right, front, and back of the model, and set the initial displacement to zero.

(2) Set the horizontal and vertical initial displacements of the top and bottom boundaries of the model to be zero.

The stress condition of the model is determined by the stress condition, and the horizontal displacement constraint condition is taken in the $X$ direction:

$$
\begin{aligned}
u_{x=0} & =0, \\
u_{x=401} & =0 .
\end{aligned}
$$

Take the horizontal displacement constraint condition in the $Y$ direction:

$$
\begin{aligned}
u_{y=0} & =0, \\
u_{y=390} & =0 .
\end{aligned}
$$

Set the vertical displacement constraint conditions on the top and bottom boundaries:

$$
u_{z=0}=0
$$

When considering the geological structural stress, the load applied to the model is the structural stress. According to the field measured data, the stress servo control program is used to generate the initial ground stress. There are 6 boundaries in this model, where all nodes on the $Z$-axis speed plane are fixed at the bottom boundary, the $X$-axis speed of the model is fixed at the left and right twice, and the $Y$-axis speed model is fixed at the front and rear sides (Figure 4).

According to the lithology and engineering geological characteristics of the simulation area, fully considering the size effect, the final size of the model is $401 \mathrm{~m} \times 390 \mathrm{~m} \times 318 \mathrm{~m}$, and the grid densification is carried out in the key research area. Finally, a total of 225733 grids are established, and the overall model of four times of distributed excavation is established. The third and fourth excavation are two steps of the open pit, respectively. The model information and excavation sequence are shown in Figure 5.

3.2. Numerical Simulation Analysis of Slope Stability under Excavation Conditions. Under the influence of its own load, the stratum in natural state will be affected by the relevant stress. Therefore, before excavation, the linear elastic model should be used to carry out the self-balance under the condition of gravity field, and then the calculation should be carried out in the elastic-plastic stage of Moore Coulomb model, with the maximum unbalanced force less than the convergence criterion $1 e^{-5} \mathrm{~N}$ as the end mark.

Figure 6 shows the stress-strain nephogram in $Z$ direction after the initial in situ stress of limestone mine, in which the cold color indicates larger strain and the warm color indicates smaller strain. Figure $(6 a)$ is the stress nephogram of $Z$-direction generated by initial in situ stress. It is obvious that the stress field in the mine presents a relatively uniform distribution, which is consistent with the actual situation. It can be seen from Figure 6(b) that, after the initial in situ stress, its $Z$-axis displacement gradually increases from the bottom to the top, and the displacement field is evenly distributed. The maximum settlement is $4.48 \mathrm{~cm}$, which mainly occurs at the top of the terrain on the right upper part of the mine. It shows that the consolidation settlement of the model is sufficient under natural condition.

3.2.1. First Excavation. After the in situ stress is balanced, the displacement field and velocity field generated are reset to zero, and the Mohr-Coulomb model is used to simulate the stress and strain state of the studied mine in the excavation area. The following is the stress and strain cloud diagram after the first excavation of the mine after the ground stress is generated, as shown in Figures 7 and 8. 


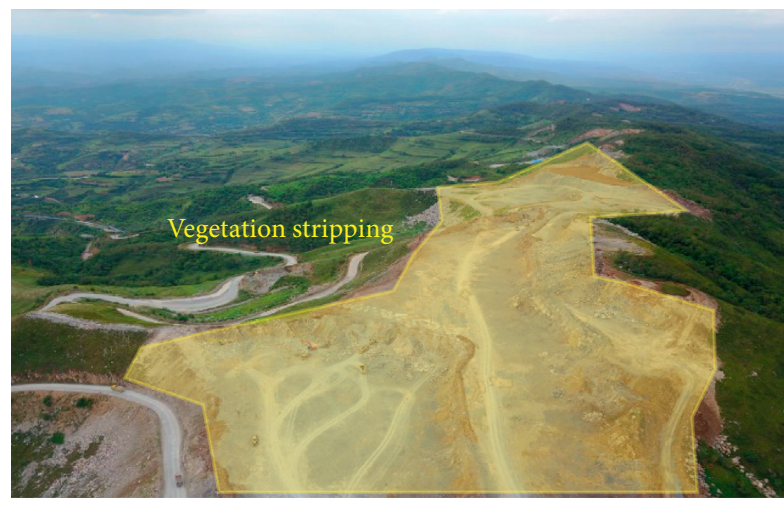

(a)

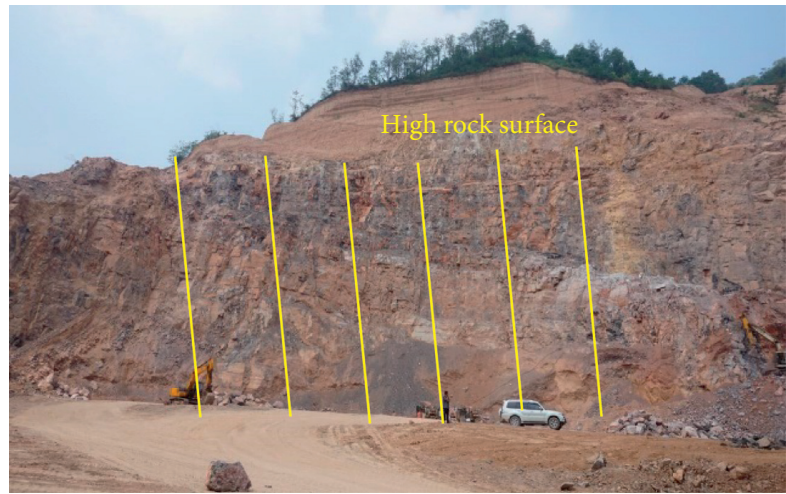

(c)

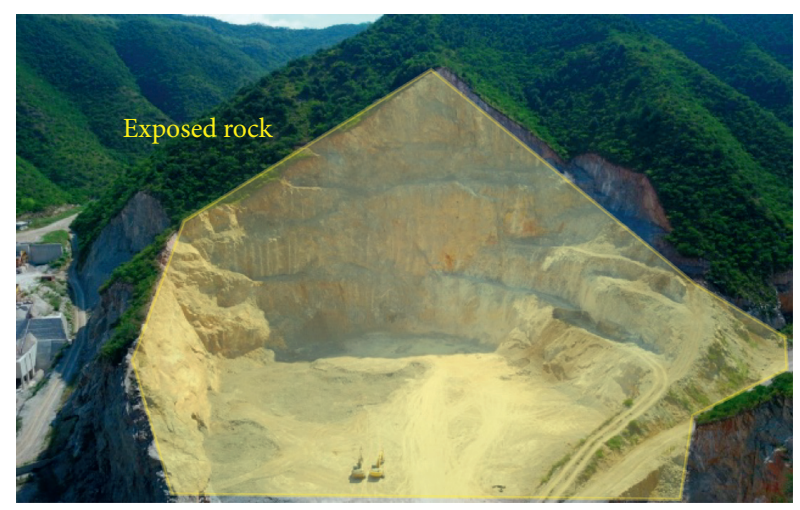

(b)

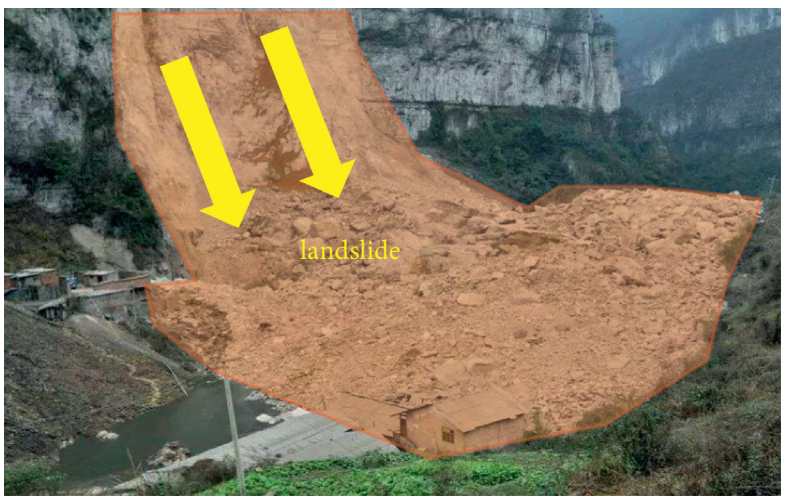

(d)

FIgURE 2: Main geological disasters in Weibei area. (a) Vegetation stripping. (b) Exposed rock. (c) High rock surface. (d) Landslide.

SketchUp captures terrain and exports 3D models

Rhino builds a 3D geological model

Hypermesh software for model meshing

Generate FLAC model and perform excavation calculation

FIgURE 3: The modeling process.
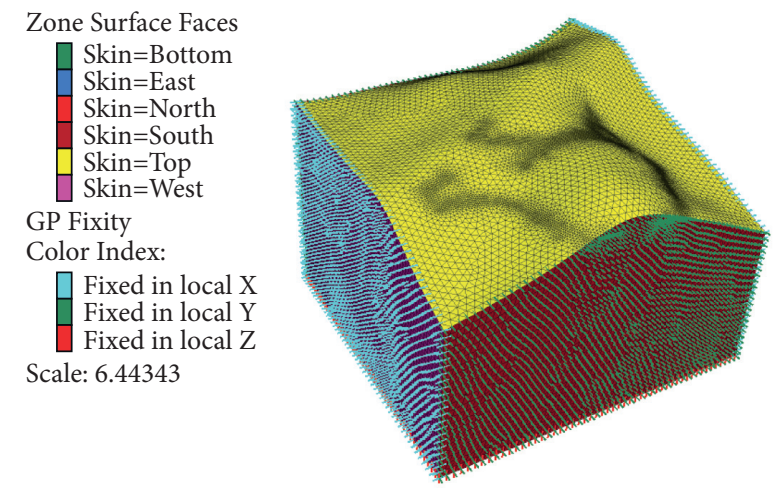

Figure 4: Boundary constraint condition.
After the excavation is completed, the stress around the excavation area is released and the stress value is reduced due to the unloading effect (Figure 7). The stress concentration phenomenon at the foot of the excavation slope can be clearly seen from the stress nephogram in $X$ and $Y$ directions. The stress in the surface of the mine excavation area is mainly between $-1.18 \mathrm{MPa}$ and $0.51 \mathrm{MPa}$, and the stress in $Z$ direction is mainly between $-1.35 \mathrm{MPa}$ and $-0.71 \mathrm{MPa}$. The initial stress state is basically maintained in the position away from the mine excavation area.

As shown in Figure 8, after the excavation of the first layer, obvious rebound occurs in the excavation area, in which the displacement rebound amount in $Z$ direction at the foot of the slope in the excavation area is the largest, with the maximum displacement of $0.11 \mathrm{~cm}$. The slope top in the excavation area presents the trend of sliding in $X$ direction, with the maximum displacement of $0.19 \mathrm{~cm}$. In the displacement vector diagram (the displacement vector cloud diagram can represent the displacement size and the direction of the overall displacement), the arrow direction represents the displacement direction of the solution unit.

3.2.2. Second Excavation. After the balance of the first excavation, the second excavation is simulated, and the stressstrain nephogram is shown in Figures 9 and 10.

After the second excavation, the stress distribution is similar to that of the first excavation, and there is obvious stress concentration at the foot of the slope (Figure 9). The 


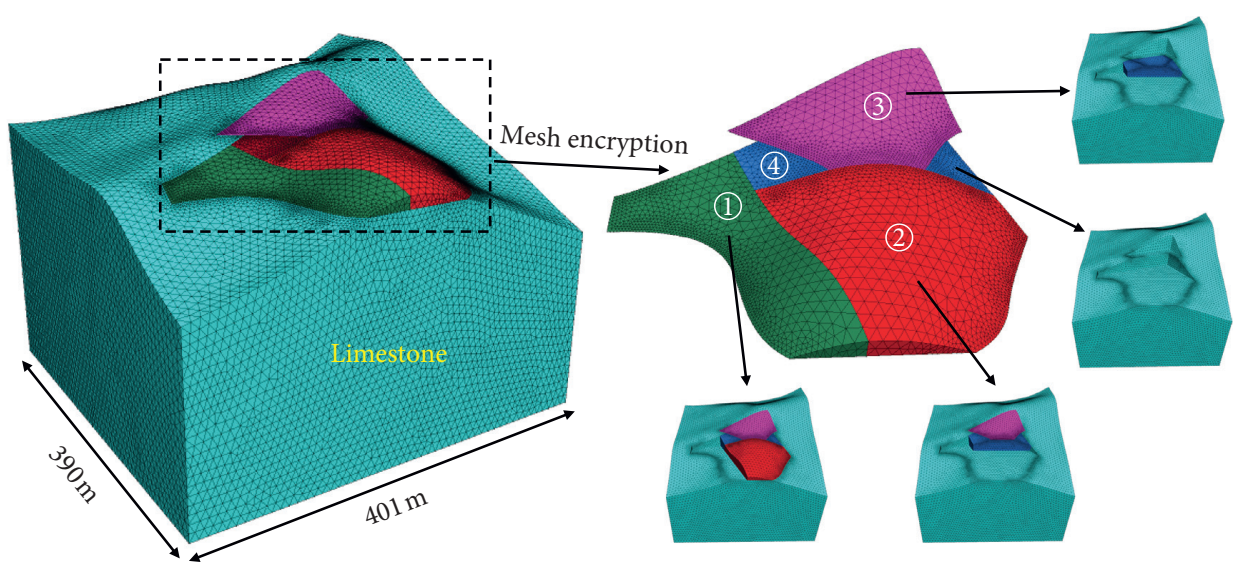

Figure 5: Model size and excavation sequence.

Zone ZZ Stress

Calculated by: Constant
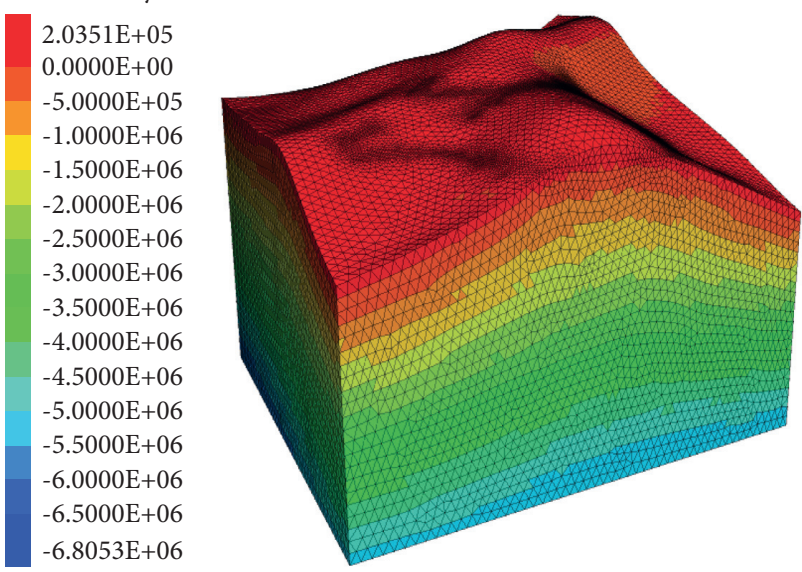

(a)

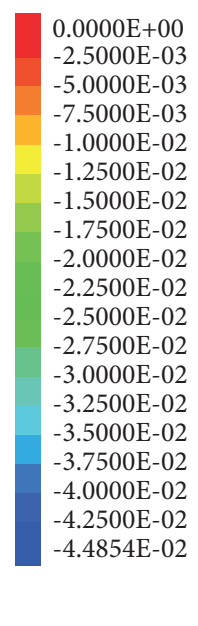

$2.5000 \mathrm{E}-03$

$-5.0000 \mathrm{E}-03$

$7.5000 \mathrm{E}-03$

$-1.0000 \mathrm{E}-02$

$-1.5000 \mathrm{E}-02$

$-1.7500 \mathrm{E}-02$

$-2.0000 \mathrm{E}-02$

$2.2500 \mathrm{E}-02$

$2.5000 \mathrm{E}-02$

$-2.7500 \mathrm{E}-02$

$-3.0000 \mathrm{E}-02$

$3.2500 \mathrm{E}-02$

$-3.5000 \mathrm{E}-02$

$-3.7500 \mathrm{E}-02$

$4.0000 \mathrm{E}-02$

$4.2500 \mathrm{E}-02$

$-4.4854 \mathrm{E}-02$

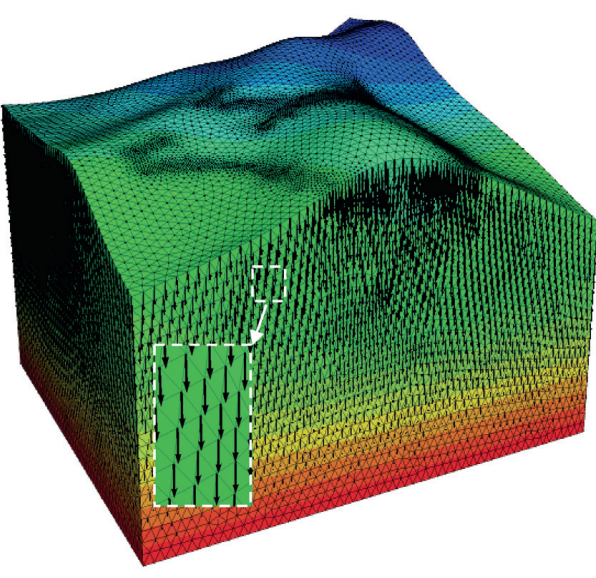

(b)

FIGURE 6: Stress-strain nephogram after initial in situ stress. (a) Z-direction stress nephogram and (b) Z-direction strain nephogram.

Zone XX Stress

Calculated by: Constant

$6.1768 \mathrm{E}+05$
$6.0000 \mathrm{E}+05$
$5.0000 \mathrm{E}+05$
$4.0000 \mathrm{E}+05$
$3.0000 \mathrm{E}+05$
$2.0000 \mathrm{E}+05$
$1.0000 \mathrm{E}+05$
$0.0000 \mathrm{E}+00$
$-1.0000 \mathrm{E}+05$
$-2.0000 \mathrm{E}+05$
$-3.0000 \mathrm{E}+05$
$-4.0000 \mathrm{E}+05$
$-5.0000 \mathrm{E}+05$
$-6.0000 \mathrm{E}+05$
$-7.0000 \mathrm{E}+05$
$-8.0000 \mathrm{E}+05$
$-9.0000 \mathrm{E}+05$
$-1.0000 \mathrm{E}+06$
$-1.1000 \mathrm{E}+06$
$-1.1824 \mathrm{E}+06$

$-1.1824 \mathrm{E}+06$

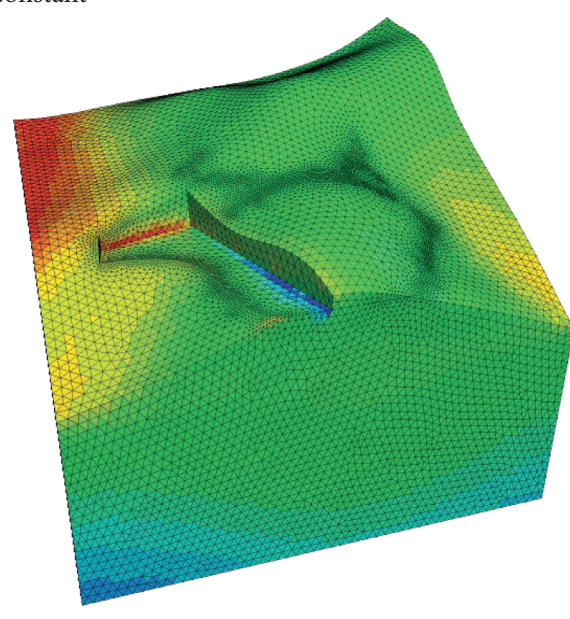

(a)
Zone ZZ Stress

Calculated by: Constant

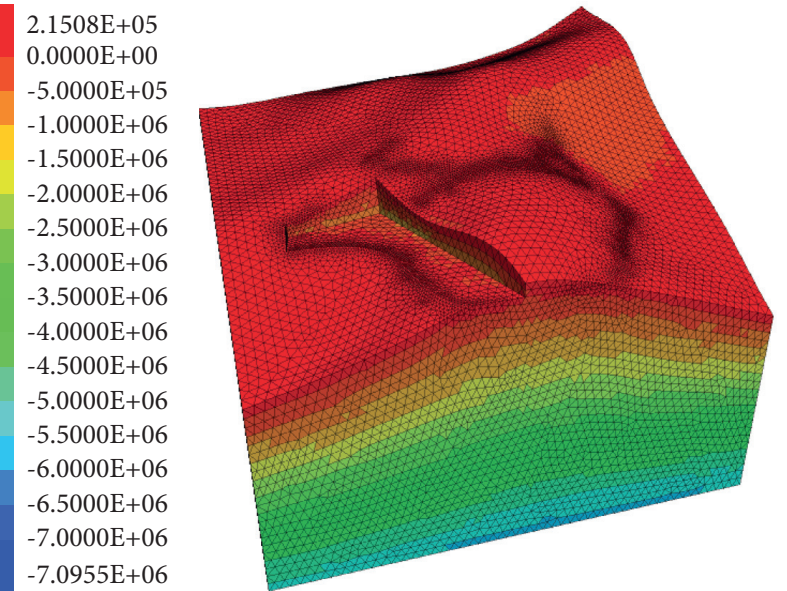

(b)

Figure 7: Stress nephogram after first excavation. (a) $X$-direction stress nephogram and (b) Z-direction stress nephogram. 
Zone X Displacement

$3.5594 \mathrm{E}-03$
$3.5000 \mathrm{E}-03$
$3.0000 \mathrm{E}-03$
$2.5000 \mathrm{E}-03$
$2.0000 \mathrm{E}-03$
$1.5000 \mathrm{E}-03$
$1.0000 \mathrm{E}-03$
$5.0000 \mathrm{E}-04$
$0.0000 \mathrm{E}+00$
$-5.0000 \mathrm{E}-04$
$-1.0000 \mathrm{E}-03$
$-1.5000 \mathrm{E}-03$
$-1.8648 \mathrm{E}-03$

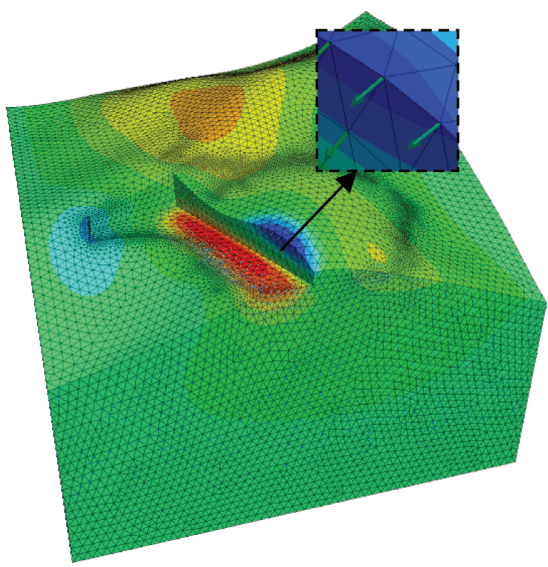

(a)
Zone Z Displacement

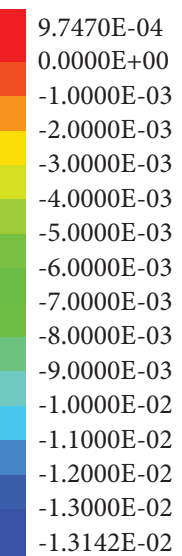

$-1.3142 \mathrm{E}-02$

FiguRE 8: Strain nephogram after first excavation. (a) $X$-direction strain nephogram and (b) Z-direction strain nephogram.

Zone XX Stress

Calculated by: Constant

$8.9564 \mathrm{E}+05$
$8.0000 \mathrm{E}+05$
$7.0000 \mathrm{E}+05$
$6.0000 \mathrm{E}+05$
$5.0000 \mathrm{E}+05$
$4.0000 \mathrm{E}+05$
$3.0000 \mathrm{E}+05$
$2.0000 \mathrm{E}+05$
$1.0000 \mathrm{E}+05$
$0.0000 \mathrm{E}+00$
$-1.0000 \mathrm{E}+05$
$-2.0000 \mathrm{E}+05$
$-3.0000 \mathrm{E}+05$
$-4.0000 \mathrm{E}+05$
$-5.0000 \mathrm{E}+05$
$-6.0000 \mathrm{E}+05$
$-7.0000 \mathrm{E}+05$
$-8.0000 \mathrm{E}+05$
$-9.0000 \mathrm{E}+05$
$-9.1310 \mathrm{E}+05$

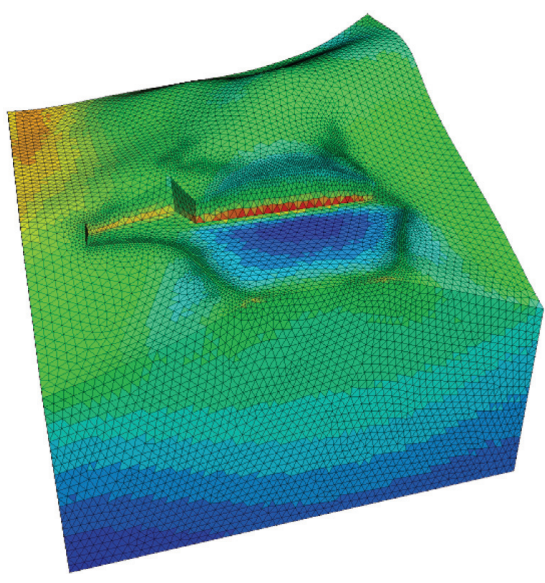

(a)

Zone ZZ Stress

Calculated by: Constant

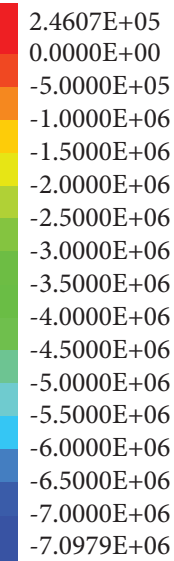

$-7.0979 \mathrm{E}+06$

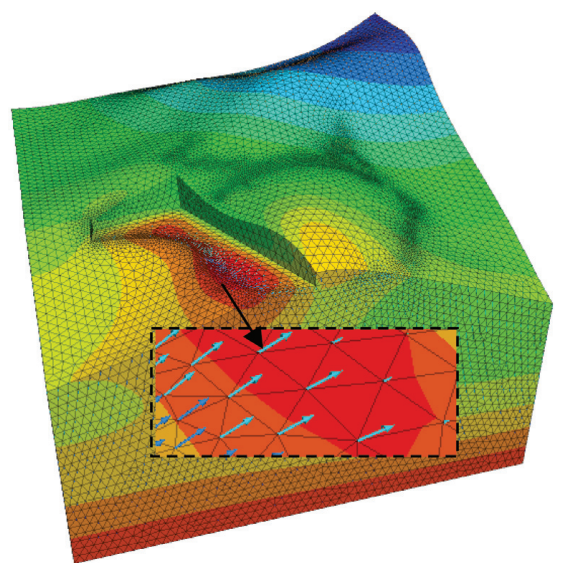

(b)

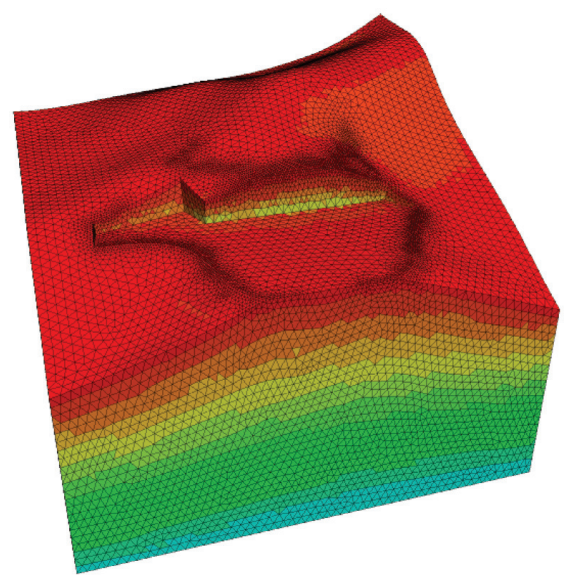

(b)

Figure 9: Stress nephogram after second excavation. (a) X-direction stress nephogram and (b) Z-direction stress nephogram.
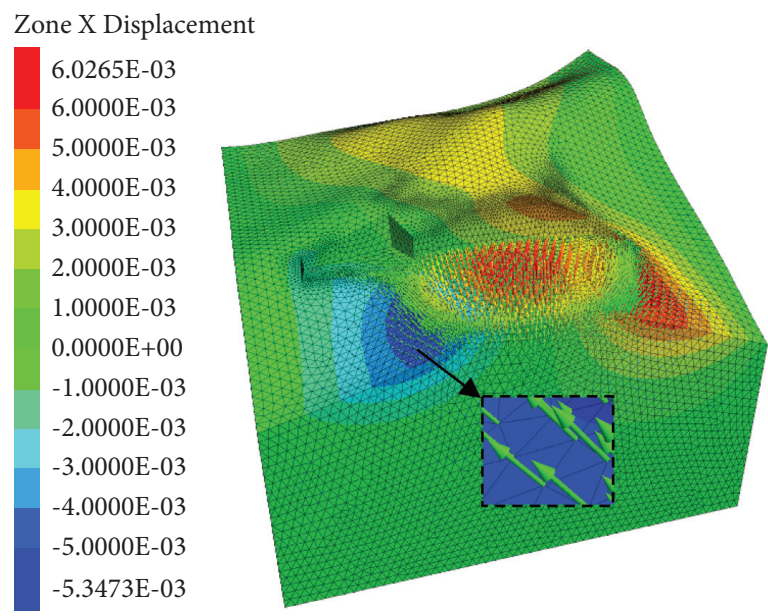

(a)

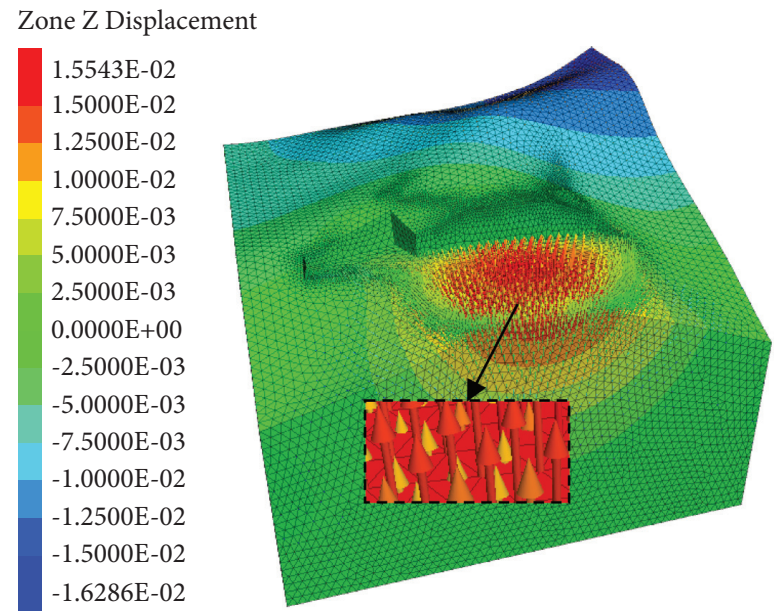

(b)

FIgURE 10: Strain nephogram after second excavation. (a) X-direction strain nephogram and (b) Z-direction strain nephogram. 
stress distribution in $Z$ direction is relatively uniform, and the stress value increases gradually from surface to core. The stress in $X$ direction is mainly between $-0.23 \mathrm{MPa}$ and $0.67 \mathrm{MPa}$, and the stress in $Z$ direction is mainly between $-2.23 \mathrm{MPa}$ and $0.11 \mathrm{MPa}$.

There is a small amount of $X$-direction displacement on the slope outside the excavation area in Figure 10, which shows the trend of sliding to both sides. The maximum displacement on the left side of the excavation area is $0.53 \mathrm{~cm}$, and the maximum displacement on the right side is $0.59 \mathrm{~cm}$. In the excavation area, there is a positive displacement in $Z$ direction, because the slope rebounds due to the unloading effect in the excavation area. In the center of the excavation area, the displacement rebound in $Z$ direction is the largest, and the maximum displacement in $Z$ direction is $1.56 \mathrm{~cm}$.

3.2.3. Third Excavation. After the second excavation balance, the third excavation simulation of the mine is carried out, that is, the excavation of the first step. The stress-strain nephogram is shown in Figures 11 and 12.

After the third excavation, the stress distribution is different from that of the first two (Figure 11). There are obvious stress concentrations at the toe of the excavation and the residual toe of the second excavation; the maximum stress concentration at the toe of the upper slope is $0.42 \mathrm{MPa}$, and the maximum stress concentration at the bottom is $0.59 \mathrm{MPa}$, which shows that the stress concentration in the lower layer is more serious than that in the upper layer. The stress distribution in $Z$ direction is relatively uniform, and the stress value increases gradually from the surface to inner core. The stress in $X$ direction is mainly between $-0.52 \mathrm{MPa}$ and $-0.18 \mathrm{MPa}$, and the stress in $Z$ direction is mainly between $-0.19 \mathrm{MPa}$ and $-0.01 \mathrm{MPa}$.

Besides the first step excavation area and the second excavation area, the slope still shows $X$-direction sliding (Figure 12). The maximum displacement on the left side of the upper excavation area is $0.23 \mathrm{~cm}$, and the maximum displacement on the right side is $0.54 \mathrm{~cm}$; the maximum displacement on the left side of the lower second excavation area is $0.58 \mathrm{~cm}$, and the maximum displacement on the right side is $0.62 \mathrm{~cm}$. Within the excavation area, the maximum displacement caused by the bottom heave is $0.6 \mathrm{~cm}$ in the upper layer and $1.6 \mathrm{~cm}$ in the lower layer. The overall analysis shows that the excavation of the first step has less impact on the upper mine than on the lower mine. The reason may be that the excavation has less soil and the impact is not enough to offset the effect of large-scale excavation.

3.2.4. Fourth Excavation. After the third excavation balance, the first step of the quarry has been formed. Continue to carry out the fourth excavation simulation of the mine, that is, the excavation of the second step. The stress-strain nephogram is shown in Figures 13 and 14.

After the excavation of the second step, the stress distribution is similar to that of the first step (Figure 13). There is an obvious stress concentration at the foot of the second step and the first step; the maximum stress concentration in the upper layer is $0.29 \mathrm{MPa}$, and the maximum stress concentration in the lower layer is $0.79 \mathrm{MPa}$. It can be seen that the stress concentration in the lower layer is still more serious than that in the upper layer. The stress distribution in $Z$ direction is relatively uniform, and the stress value increases gradually from surface to core. The stress in $X$ direction is mainly between $-0.78 \mathrm{MPa}$ and $-0.15 \mathrm{MPa}$, and the stress in $Z$ direction is mainly between $-0.21 \mathrm{MPa}$ and $-0.02 \mathrm{MPa}$.

After the excavation of the second step in Figure 14, the slope outside the excavation area still shows $X$-direction sliding; the maximum displacement on the left side of the excavation area is $0.72 \mathrm{~cm}$, and the maximum displacement on the right side is $0.75 \mathrm{~cm}$. Within the excavation area, the maximum displacement of the floor heave caused by the excavation of the second step is $2.1 \mathrm{~cm}$, the maximum value appears in the center of the excavation area, and the floor heave does not appear in the excavation area of the first step.

3.3. Stress-Strain Monitoring and Slope Reinforcement Location Selection. In order to compare the stress concentration and displacement difference between the first step and the second step more intuitively, and to strengthen the slope effectively, the monitoring points are set up for the numerical model. A total of 13 strain monitoring points are arranged, including 6 first steps and 7 second steps, which are evenly distributed in the area with obvious stress concentration at the foot of the slope, $1.5 \mathrm{~m}$ high from the step, and the distance between the two monitoring points is $30 \mathrm{~m}$ (the influence range of reinforcement is $30 \mathrm{~m}$ ). A total of 41 displacement monitoring points are arranged, including 14 first steps and 27 second steps. The height from the step is $5 \mathrm{~m}$, and the distance between the two monitoring points is $30 \mathrm{~m}$, as shown in Figure 15.

As shown in Figures 16(a) and 16(b) stress-strain monitoring curves, the stress and strain of monitoring points are in an increasing state after the completion of the first three excavations. After the fourth excavation, because part of the soil of the first step was excavated, the stress concentration became smaller, while the maximum stress concentration appeared at the foot of the second step, and the floor heave also increased. It can be concluded that the best reinforcement monitoring point is near the corner of the second step, followed by the foot of the first step.

\section{Slope Stability Analysis Based on SlopeLE}

4.1. Introduction of SlopeLE. It can simply calculate the stability of the slope and the remaining sliding force, or automatically search for the minimum stability coefficient or the maximum remaining sliding force of the slope, which is the most important function of the slope calculation software SlopeLE. This software is widely used because of its simple interface, simple modeling process, easy operation, and other characteristics. The intermediate data in the calculation process can also be listed item by item in the form of a list, and the table can correspond to the diagram, 
Zone XX Stress

Calculated by: Constant

$6.1011 \mathrm{E}+05$
$6.0000 \mathrm{E}+05$

$5.0000 \mathrm{E}+05$

$4.0000 \mathrm{E}+05$

$3.0000 \mathrm{E}+05$

$2.0000 \mathrm{E}+05$

$1.0000 \mathrm{E}+05$

$0.0000 \mathrm{E}+00$

$-1.0000 \mathrm{E}+05$

$-2.0000 \mathrm{E}+05$

$-3.0000 \mathrm{E}+05$

$-4.0000 \mathrm{E}+05$

$-5.0000 \mathrm{E}+05$

$-6.0000 \mathrm{E}+05$

$-7.0000 \mathrm{E}+05$

$-8.0000 \mathrm{E}+05$

$-9.0000 \mathrm{E}+05$

$-9.1798 \mathrm{E}+05$

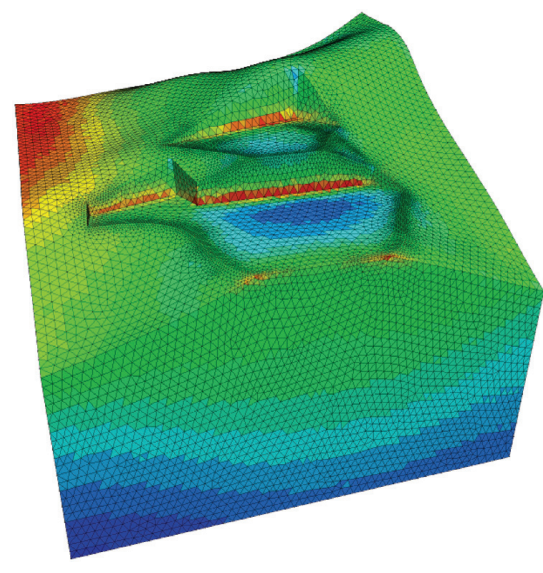

(a)
Zone ZZ Stress

Calculated by: Constant

$2.6022 \mathrm{E}+05$

$0.0000 \mathrm{E}+00$

$-5.0000 \mathrm{E}+05$

$-1.0000 \mathrm{E}+06$

$-1.5000 \mathrm{E}+06$

$-2.0000 \mathrm{E}+06$

$-2.5000 \mathrm{E}+06$

$-3.0000 \mathrm{E}+06$

$-3.5000 \mathrm{E}+06$

$-4.0000 \mathrm{E}+06$

$-4.5000 \mathrm{E}+06$

$-5.0000 \mathrm{E}+06$

$-5.5000 \mathrm{E}+06$

$-6.0000 \mathrm{E}+06$

$-6.5000 \mathrm{E}+06$

$-7.0000 \mathrm{E}+06$

$-7.0826 \mathrm{E}+06$

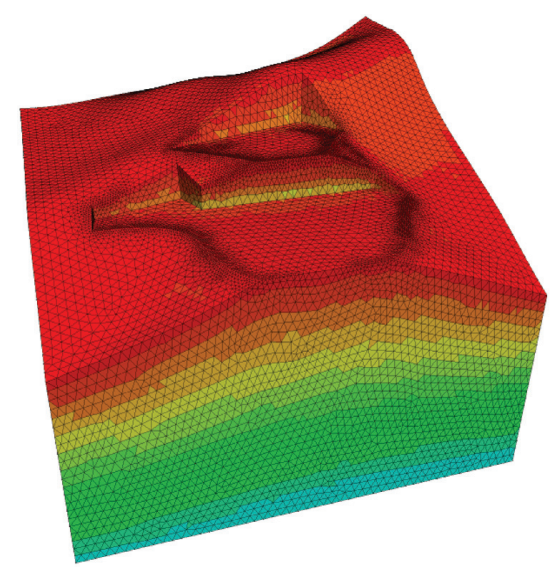

(b)

Figure 11: Stress nephogram after third excavation. (a) $X$-direction stress nephogram and (b) Z-direction stress nephogram.

Zone X Displacement

$6.8565 \mathrm{E}-03$
$6.0000 \mathrm{E}-03$
$5.0000 \mathrm{E}-03$
$4.0000 \mathrm{E}-03$
$3.0000 \mathrm{E}-03$
$2.0000 \mathrm{E}-03$
$1.0000 \mathrm{E}-03$
$0.0000 \mathrm{E}+00$
$-1.0000 \mathrm{E}-03$
$-2.0000 \mathrm{E}-03$
$-3.0000 \mathrm{E}-03$
$-4.0000 \mathrm{E}-03$
$-5.0000 \mathrm{E}-03$
$-5.7544 \mathrm{E}-03$

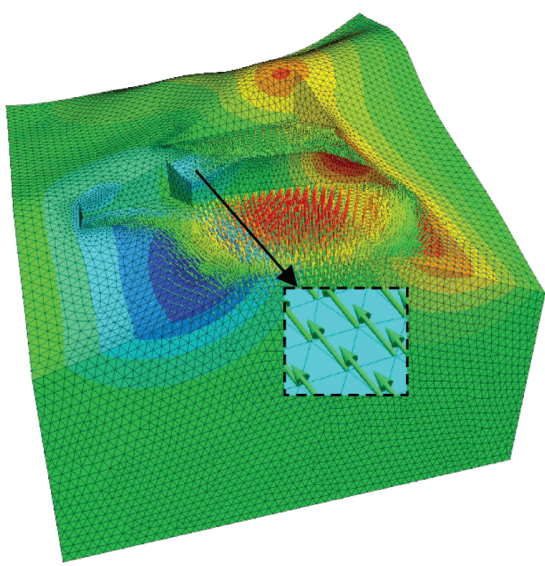

(a)

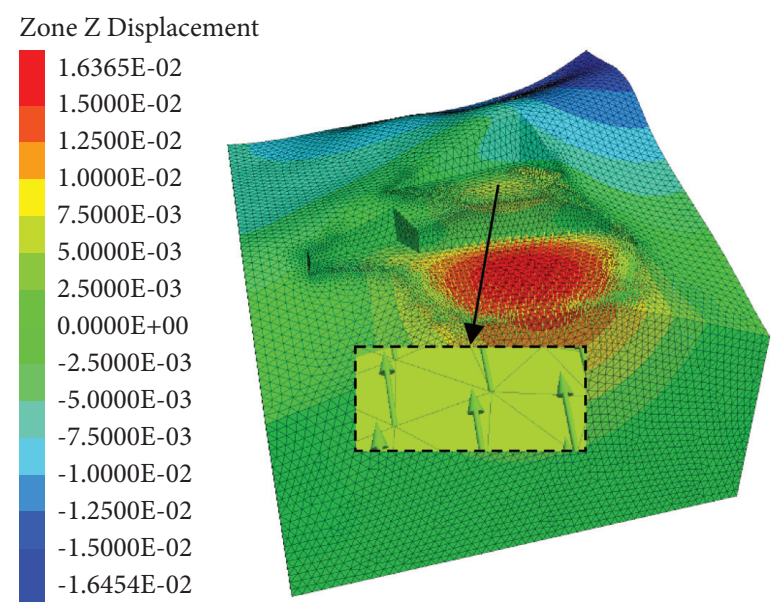

(b)

FiguRE 12: Strain nephogram after third excavation. (a) $X$-direction strain nephogram and (b) $Z$-direction strain nephogram.

Zone XX Stress

Calculated by: Constant

$7.9228 \mathrm{E}+05$
$6.0000 \mathrm{E}+05$
$4.0000 \mathrm{E}+05$
$2.0000 \mathrm{E}+05$
$0.0000 \mathrm{E}+00$
$-2.0000 \mathrm{E}+05$
$-4.0000 \mathrm{E}+05$
$-6.0000 \mathrm{E}+05$
$-8.0000 \mathrm{E}+05$
$-1.0000 \mathrm{E}+06$
$-1.2000 \mathrm{E}+06$
$-1.4000 \mathrm{E}+06$
$-1.6000 \mathrm{E}+06$
$-1.6095 \mathrm{E}+06$

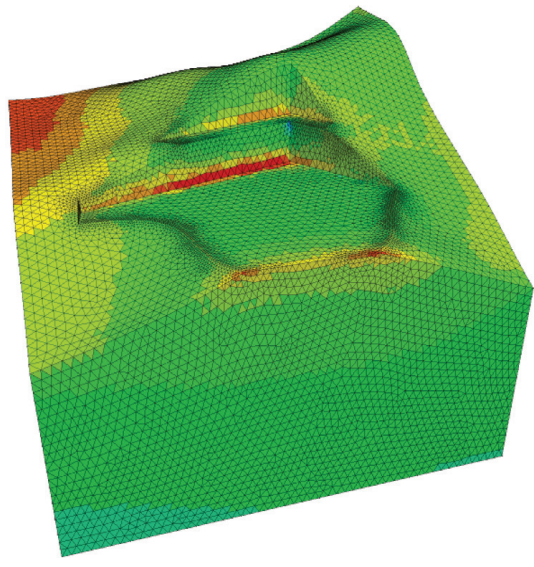

(a)
Zone ZZ Stress

Calculated by: Constant

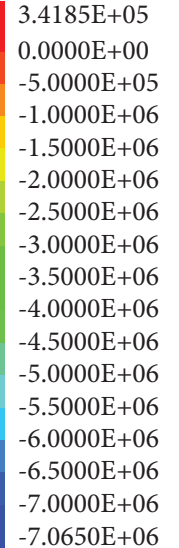

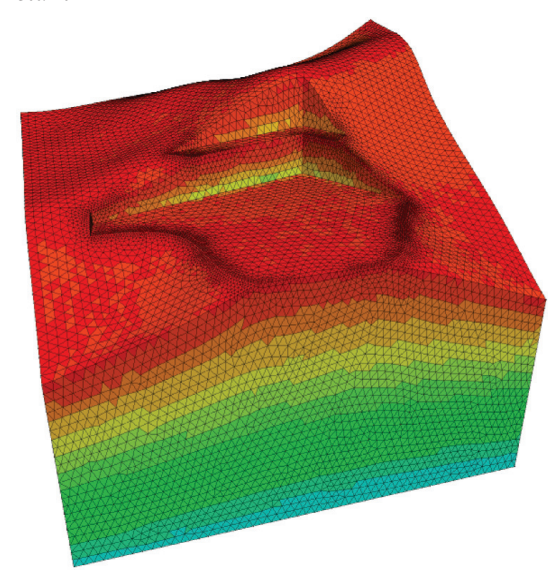

(b)

Figure 13: Stress nephogram after forth excavation. (a) $X$-direction stress nephogram and (b) Z-direction stress nephogram. 
Zone X Displacement

$7.6087 \mathrm{E}-03$
$7.0000 \mathrm{E}-03$
$6.0000 \mathrm{E}-03$
$5.0000 \mathrm{E}-03$
$4.0000 \mathrm{E}-03$
$3.0000 \mathrm{E}-03$
$2.0000 \mathrm{E}-03$
$1.0000 \mathrm{E}-03$
$0.0000 \mathrm{E}+00$
$-1.0000 \mathrm{E}-03$
$-2.0000 \mathrm{E}-03$
$-3.0000 \mathrm{E}-03$
$-4.0000 \mathrm{E}-03$
$-5.0000 \mathrm{E}-03$
$-6.0000 \mathrm{E}-03$
$-7.0000 \mathrm{E}-03$
$-7.2799 \mathrm{E}-03$

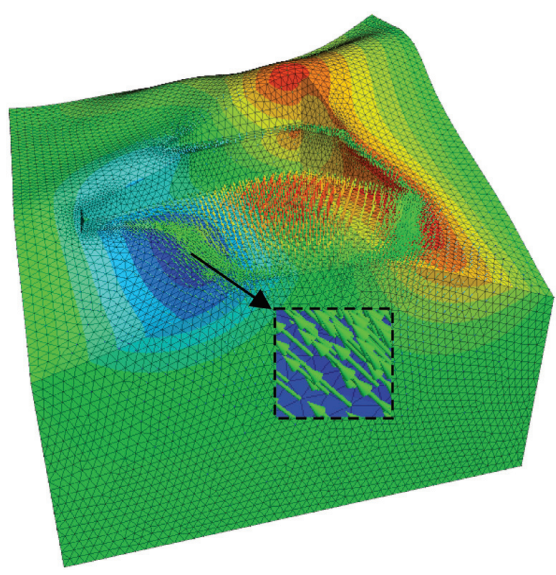

(a)

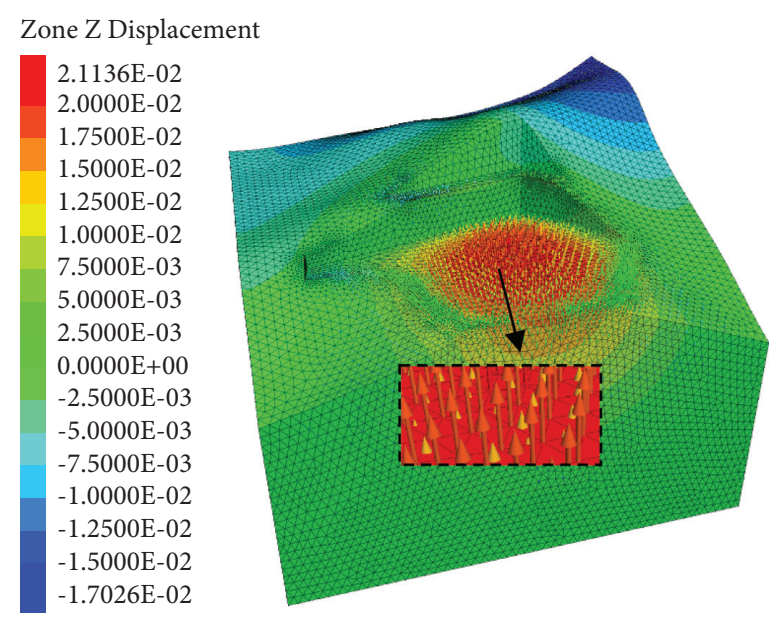

(b)

FIgURE 14: Strain nephogram after forth excavation. (a) $X$-direction strain nephogram and (b) Z-direction strain nephogram.

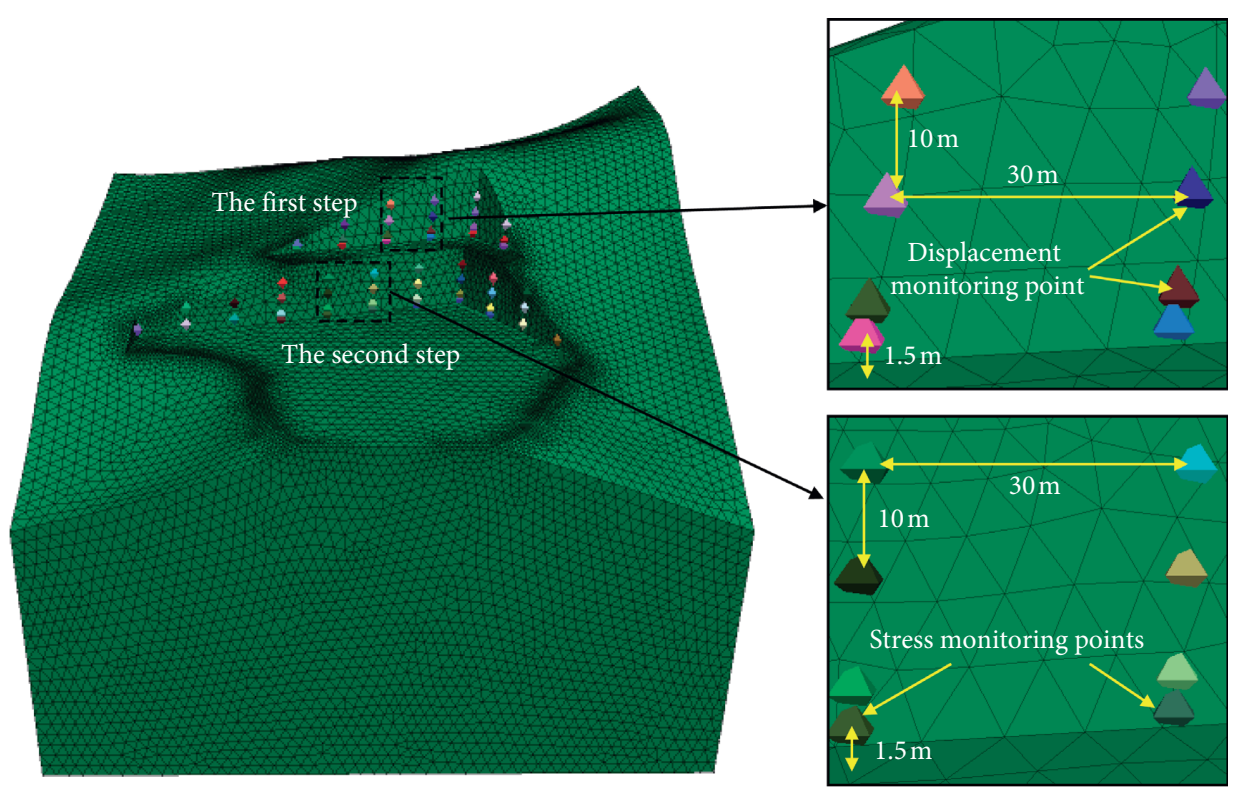

FIGURE 15: Arrangement of stress and strain monitoring points.

which provides convenience for the check work. Another advantage of SlopeLE software is that it makes full use of AutoCAD's powerful editing functions and realizes easy and quick export and import of AutoCAD graphics data (Figure 17).

The main calculation methods of SlopeLE software are divided into Swedish section method, simplified Bishop method, transfer coefficient method, engineering group method, Spencer method, and Morgenstern-Price method. The following are three common calculation methods.

4.1.1. Swedish Division. The principle of Swedish division method is very simple, and the amount of calculation is very small, so it has been widely used. It is assumed that the circular arc is a sliding surface, and the sliding body is divided into several rigid vertical soil strips. It is considered that the force between the strips is very small, which will not affect the slope sliding and can be ignored, and the safety factor can be calculated only through the balance of the whole moment of sliding soil. Therefore, the stability safety factor $F_{S}$ under the Swedish slice method (without considering pore water pressure) can be written as

$$
F_{s}=\frac{\sum\left(c_{i} l_{i}+W_{i} \cos \alpha_{i} \tan \varphi_{i}\right)}{\sum W_{i} \sin \alpha_{i}} .
$$

Here, $c_{i}$ and $\varphi_{i}$ are, respectively, the shear strength indexes of the bottom of the $i$ th soil strip. $W_{i}, \mathrm{Li}$, and $\alpha_{i}$ are the total weight (natural bulk density for water and saturated bulk density for water), the bottom length, and the bottom dip angle of the soil strip I, respectively. 

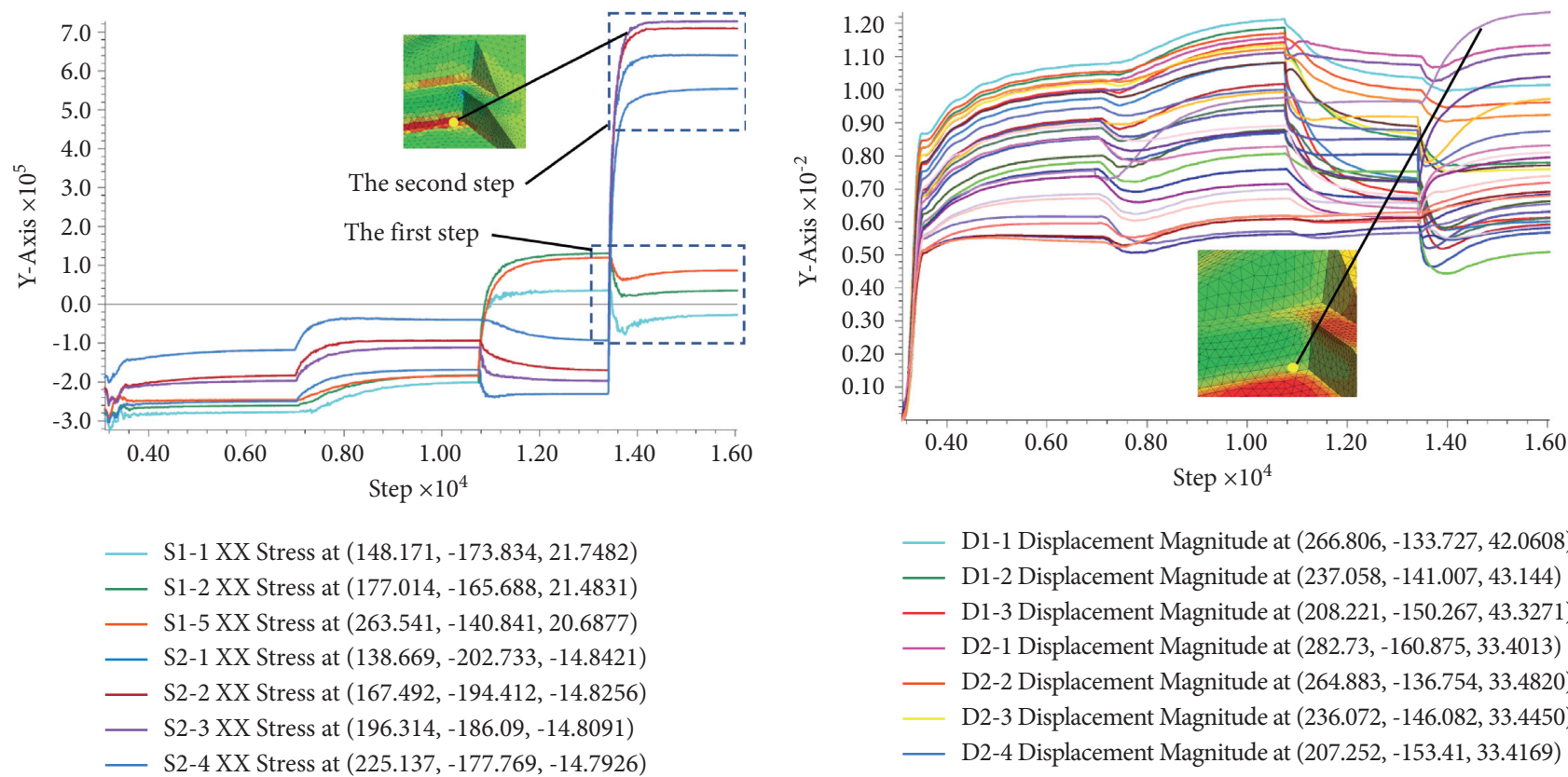

(a)

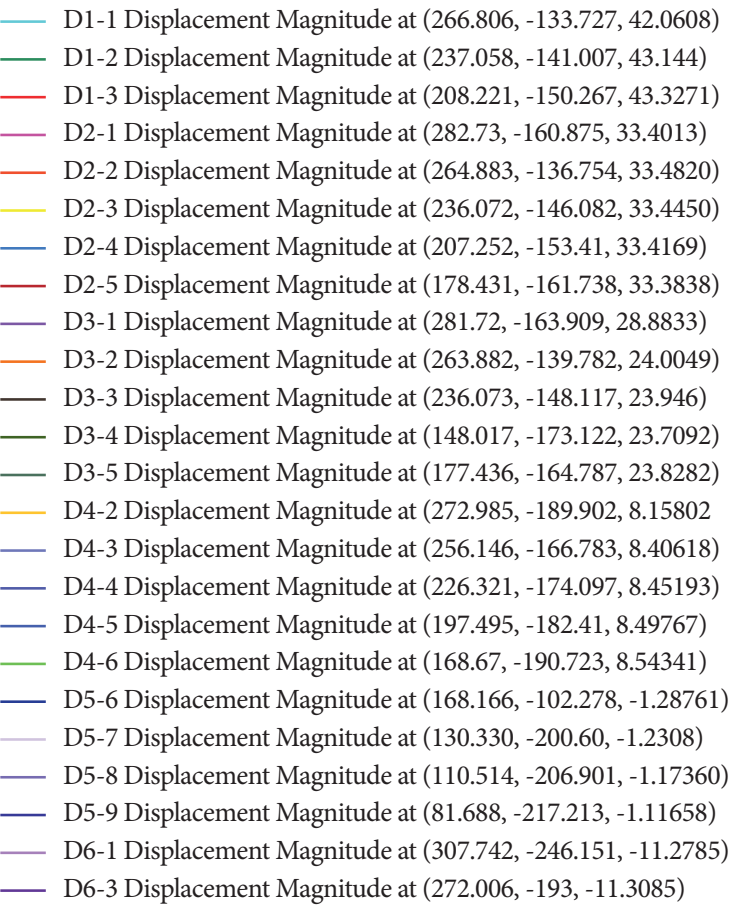

(b)

FIGURE 16: Stress strain monitoring curve. (a) Stress monitoring curve and (b) strain monitoring curve.

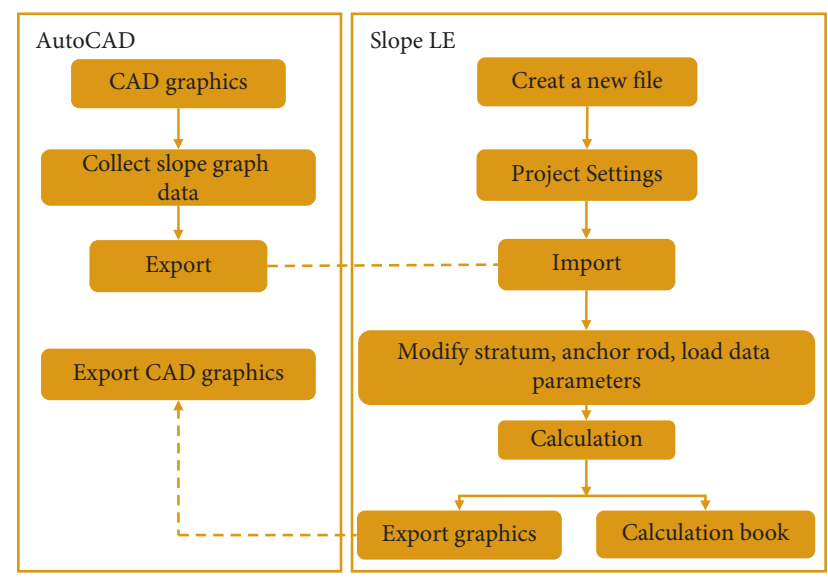

Figure 17: CAD and SlopeLE using flow chart.
4.1.2. Simplify Bishop's Method. The Bishop method is simple and has high accuracy. It is regarded as the best method to calculate the safety factor of circular sliding surface and is the most popular method in engineering. The difference between the method and the simple method is that the horizontal force between the soil strips is taken into consideration.

$$
\begin{aligned}
F_{s} & =\frac{M_{r}}{M_{s}} \\
& =\frac{\sum\left(N_{i} \tan \varphi_{i}+c_{i} l_{i}\right)}{\sum W_{i} \sin \alpha_{i}}
\end{aligned}
$$

where $M_{r}$ and $M_{s}$ are antiskid moment and sliding moment, respectively, and $N_{i}, W_{i}, \varphi_{i}$, and $\alpha_{i}$ are, respectively, the bottom normal force, gravity, friction angle, and bottom dip 
TABLE 1: Slope stability state grading table.

\begin{tabular}{|c|c|c|c|c|}
\hline Stability factor fs & Fs $<1.00$ & $1.0 \leq$ Fs $<1.05$ & $1.05 \leq$ Fs $<1.15$ & Fs $\geq 1.15$ \\
\hline Slope steady state & Unstable & Understable & Basically stable & Stable \\
\hline
\end{tabular}

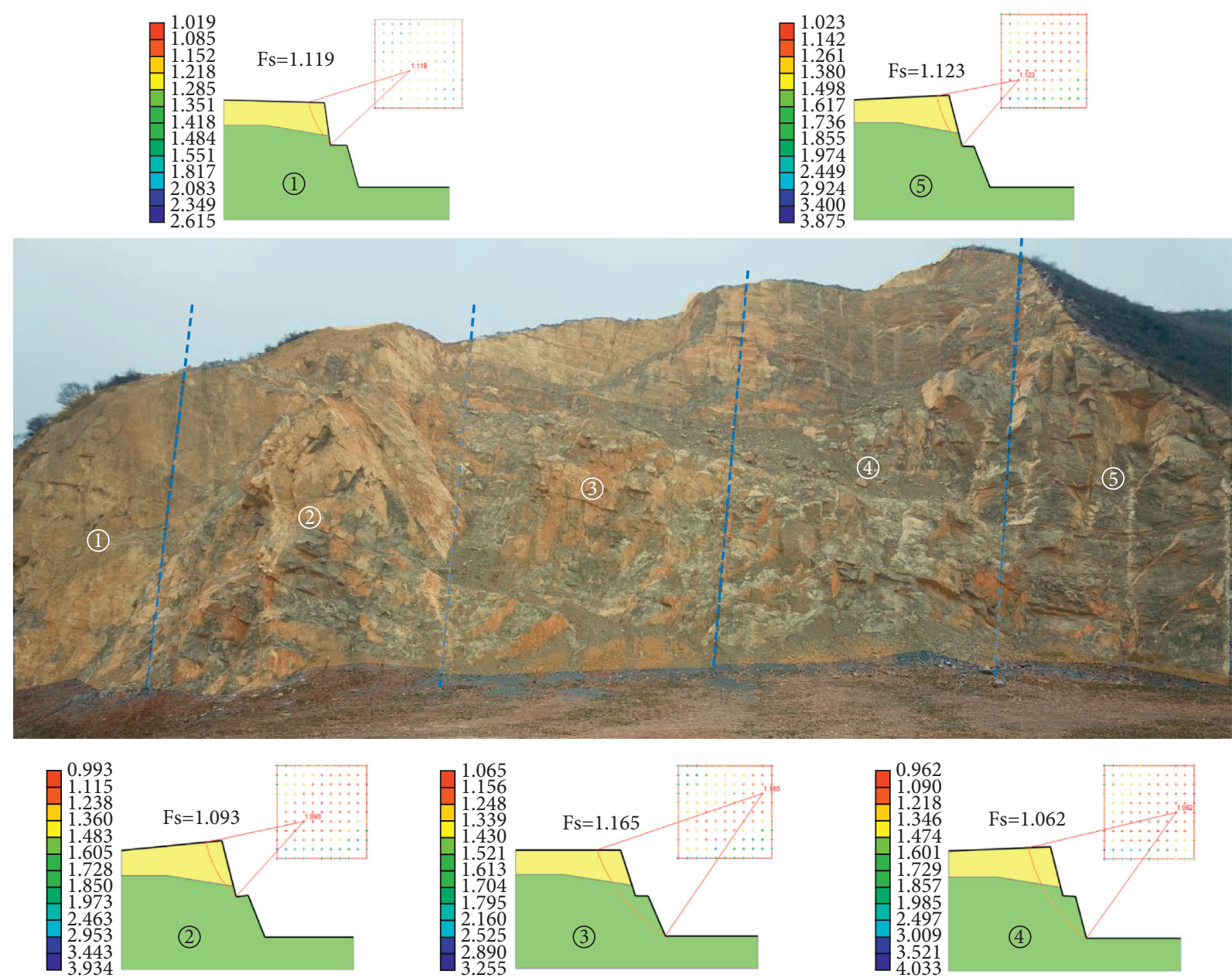

FIGURE 18: Safety factor of mine slope stability.

angle of the $i$ th soil strip. $c_{i}$ and $l_{i}$ are the cohesive force and bottom length of the $i$-th soil strip, respectively.

\subsubsection{Transfer Coefficient Method. Since computers were} not widely used in the past, the explicit solution of the transfer coefficient (KT load increase) appeared, and the transfer coefficient was simplified. Assume that the safety factor in the transfer coefficient is 1 , which simplifies the calculation and is more convenient to solve. It has been widely used in China, and a lot of experience has been obtained in how to value the safety factor. Because the explicit method adopts the method of increasing the sliding force, the calculation error is large. The specific calculation formula is as follows:

$$
\begin{aligned}
& \text { residual sliding force: } E_{i}=E_{i-1} \times \psi_{i-1}+F_{s} \times T_{i}-R_{i}\left(\text { when } T_{i}<0, F_{s}=1 \text {; when } E_{i}<0, E_{i}=0\right) \text {, } \\
& \text { transfer coefficient: } \psi_{i-1}=\cos \left(\alpha_{i-1}-\alpha_{i}\right)-\sin \left(\alpha_{i-1}-\alpha_{i}\right) \times \tan \varphi_{i} .
\end{aligned}
$$

The implicit solution of the transfer coefficient method ( $\mathrm{R} / \mathrm{K}$ strength reduction) is also called the strength reduction safety factor method. In the stability analysis using the implicit solution method, the slip surface strength parameter is firstly reduced by Fs times until the residual slip force of the last band is 0 . At this point, the safety factor of the 


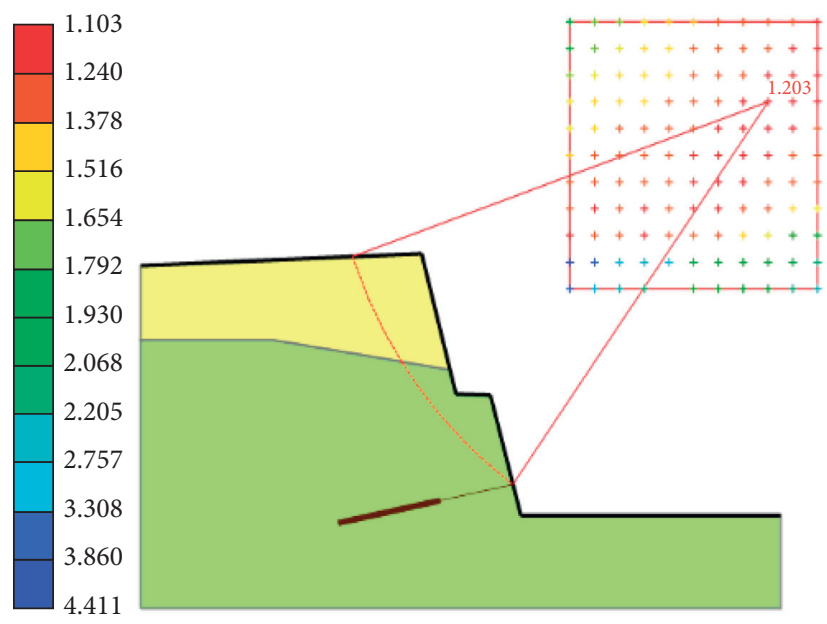

FiguRE 19: Safety factor after reinforcement.

strength reduction is the stability factor of the landslide. The specific calculation formula is as follows:

$$
\begin{aligned}
& \text { residual sliding force: } E_{i}=E_{i-1} \times \psi_{i-1}+T_{i}-\frac{R_{i}}{F_{s}}\left(\text { when } E_{i}<0, E_{i}=0\right) \text {, } \\
& \text { transfer coefficient: } \psi_{i-1}=\cos \left(\alpha_{i-1}-\alpha_{i}\right)-\sin \left(\alpha_{i-1}-\alpha_{i}\right) \times \frac{\tan \varphi_{i}}{F_{s}}
\end{aligned}
$$

4.2. Calculation of the Safety Factor of Mine Slope Stability. In the analysis of slope stability by many experts and scholars, the safety factor is generally used as the main standard to measure the stability of the slope, and according to this standard to carry out the corresponding slope treatment. Therefore, the value of the safety factor of the slope can have the most direct impact on the safety and engineering benefits of the slope. Generally speaking, the ratio of antisliding force and sliding force along the assumed sliding surface is called the safety factor of slope stability. According to article 9.4.6 of code for investigation of landslide prevention and control engineering, the stable state of slope should be determined according to its safety factor of stability according to Table 1 .

In order to investigate the slope stability and safety state of Weibei limestone mine research area, the study is divided into five parts along its strike, geological characteristics, and joint distribution (Figure 18). The most dangerous position of each part is taken to calculate the slope safety factor, the numerical value is compared and analyzed, and corresponding treatment measures are taken. It can be seen from Figure 18 that the safety factor of slope stability at Part 4 is the smallest, $F_{\mathrm{S}}=1.062$, which is between under stable and basically stable state. The $F_{\mathrm{S}}$ of the other four parts are $1.119,1.123,1.093$, and 1.165, respectively, which are basically stable, and the results are the same as those of FLAC3D numerical simulation part above. Therefore, the dangerous slope of Part 4 is reinforced.
Figure 19 shows the solution of safety factor of the fourth dangerous slope after reinforcement. The NPR constant resistance and large deformation anchor cable is used to reinforce the slope. The incident angle is $25^{\circ}$, the length is $30 \mathrm{~m}$, and the preloading force is $30 \mathrm{~T}$. Finally, $F_{\mathrm{S}}=1.203$, and the slope is in a stable state.

\section{Conclusions}

Due to the extremely harsh engineering geological conditions of the limestone mine in Weibei, the slope caused by blasting quarrying in the early stage is seriously deformed and the gravel piles up in large quantities, especially the slope near the south and north stope. Both research approaches of engineering geology in mining areas and the comprehensive treatment measures of limestone slope are of certain significance to the development of mining technology and enrichment of scientific theories. They are summarized as follows:

(1) A three-dimensional mechanical calculation model for the main stope of Weibei Limestone Mine was established, in which a total of 13 strain monitoring points and 41 displacement monitoring points were set up. According to comprehensive judgment criteria such as displacement cloud diagram, stress cloud diagram, and the convergence of numerical calculations, and referring to the stress-strain monitoring curve, the analysis and calculation 
results show that the excavation of the main stope according to the original design will produce greater stress concentration at the slope toe of the excavation area. The final excavation may cause overall instability and damage.

(2) Use SlopeLE software to analyze the stability and safety status of the slope in the study area of Weibei Limestone Mine. The mine is divided into 5 parts along its strike, geological characteristics and joint distribution, and the most dangerous position of each part is taken to solve the slope safety factor. The minimum safety factor for slope stability is $F s=1.062$, and the rock mass is between the understable state and the basic stable state, so reinforcement measures are taken for it, and $F s=1.203$ after reinforcement.

\section{Data Availability}

The data that support the findings of this study are available from the corresponding author upon reasonable request.

\section{Conflicts of Interest}

The authors declare that there are no conflicts of interest regarding the publication of this paper.

\section{Acknowledgments}

This study was supported by the Key Laboratory of Mine Geological Hazards Mechanism and Control (no. KF201902), Funding for the Special Survey Project of the Geological Environment of Typical Limestone Mines in Weibei (no. 20180205), and the Key Research and Development Project of Zhejiang Province (no. 2019C03104).

\section{References}

[1] Q. Gao, G. L. Xue, Z. Q. Yang, and D. Chen, "Study of the equivalent identification of rock mass mechanical parameters and numerical simulation of the slope stability," Journal of China University of Mining \& Technology, vol. 44, no. 3, pp. 423-429, 2015.

[2] Q. Wang, M. C. He, S. C. Li et al., "Comparative study of model tests on automatically formed roadway and gob-side entry driving in deep coal mines," International Journal of Mining Science and Technology, vol. 31, 2021.

[3] Q. Wang, Y. Wang, M. C. He et al., "Experimental research and application of automatically formed roadway without advance tunneling," Tunnelling and Underground Space Technology, vol. 114, 2021.

[4] A. Li, F. Dai, Y. Liu, and D. Hongbo, "Dynamic stability evaluation of underground cavern sidewalls against flexural toppling considering excavation-induced damage," Tunnelling and Underground Space Technology, vol. 112, Article ID 103903, 2021.

[5] C. Qiao, G. Q. Ou, H. L. Pan, J. Wang, and Y. Yu, "Review on numerical modeling methods of debris flow," Journal of Earth Sciences and Environment, vol. 38, no. 1, pp. 134-142, 2016.

[6] H. S. Shi, D. D. Sun, and K. Wu, "Development on microstructure and numerical simulation of interfacial transition zone," Journal of the Chinese Ceramic Society, vol. 44, no. 5, pp. 678-685, 2016.

[7] D. Huang, F. X. Liu, C. Yang, and R. Q. Huang, "A numerical simulation method for time-dependent growth of cracks in rocks and its validation," Chinese Journal of Rock Mechanics and Engineering, vol. 36, no. 7, pp. 1623-1633, 2017.

[8] D. F. Chen, X. T. Feng, D. P. Xu, Q. Jiang, G.-F. Liu, and C.-L. Jian, "An equivalent numerical method for evaluating the reinforcing effectiveness of grouted bolts," Rock and Soil Mechanics, vol. 36, no. 4, pp. 1195-1204, 2015.

[9] M. Geni and R. Imin, "Modern numerical simulation methods and its practical applications in engineering," Engineering Mechanics, vol. 31, no. 4, pp. 11-18, 2014.

[10] A. H. Liu, Q. Yang, and J. P. Wu, “A practical ansys 3-D numerical simulation method for in-situ stress field," Journal of Geomechanics, vol. 19, no. 02, pp. 133-142, 2013.

[11] B. Q. Zhang, H. Zhou, H. M. Chen, and S. B. Sheng, "Timespace domain high-order finite-difference methods for seismic wave numerical simulation based on new stencils," Chinese Journal of Geophysics, vol. 59, no. 5, pp. 1804-1814, 2016.

[12] X. G. Liu, W. C. Zhu, J. Wei, and K. Guan, "Time-space domain high-order finite-difference methods for seismic wave numerical simulation based on new stencils," China Mining Magazine, vol. 25, no. 1, pp. 155-160, 2016.

[13] L. D. Mi, H. Q. Jiang, and J. J. Li, "Investigation of shale gas numerical simulation method based on discrete fracture network model," Natural Gas Geoscience, vol. 25, no. 11, pp. 1795-1803, 2014.

[14] X. R. Liu, B. Xu, Y. Q. Liu, J. Wang, and G. Lin, "Cumulative damage and stability analysis of bedding rock slope under frequent microseisms," Chinese Journal of Geotechnical Engineering, vol. 42, no. 4, pp. 632-641, 2020.

[15] L. L. Xu, Q. L. Zhang, and R. Feng, "Numerical simulation of backfill strength based on optimization of stope structural parameters," Gold Science and Technology, vol. 29, no. 3, pp. 421-432, 2021.

[16] Z. A. Jiang, Y. P. Wang, and L. G. Men, "Ventilation control of tunnel drilling dust based on numerical simulation," Journal of Central South University, vol. 28, 2021.

[17] Z. G. Tao, C. Zhu, M. C. He, and M. Karakus, "A physical modeling-based study on the control mechanisms of Negative Poisson's ratio anchor cable on the stratified toppling deformation of anti-inclined slopes," International Journal of Rock Mechanics and Mining Sciences, vol. 138, Article ID 104632, 2021.

[18] C. Zhu, M. He, M. Karakus, X. Zhang, and Z. Tao, "Numerical simulations of the failure process of anaclinal slope physical model and control mechanism of negative Poisson's ratio cable," Bulletin of Engineering Geology and the Environment, vol. 80, no. 4, pp. 3365-3380, 2021.

[19] Y. Wang, W. K. Feng, R. L. Hu, and C. H. Li, "Fracture evolution and energy characteristics during marble failure under triaxial fatigue cyclic and confining pressure unloading (FC-CPU) conditions," Rock Mechanics and Rock Engineering, vol. 54, no. 2, pp. 799-818, 2021.

[20] B. Li, R. Bao, Y. Wang, R. Liu, and C. Zhao, "Permeability evolution of two-dimensional fracture networks during shear under constant normal stiffness boundary conditions," Rock Mechanics and Rock Engineering, vol. 54, no. 3, pp. 1-20, 2021.

[21] C. B. Wang, W. Q. Ding, and Y. F. Qiao, "Development and application of hardening soil constitutive model in FLAC3D," Chinese Journal of Rock Mechanics and Engineering, vol. 33, no. 1, pp. 199-208, 2014. 
[22] S. Y. Yang, J. C. Wang, and X. P. Bie, "Comparative analysis for solving slope safety factor by ANSYS and FLAC3D," Journal of Water Resources and Architectural Engineering, vol. 8, no. 1, pp. 104-106+119, 2010.

[23] L. Feng, P. Z. Chen, and W. J. Chu, "Development of FLAC3D software computing platform based on cloud computing technology," Geotechnical Engineering Technique, vol. 33, no. 6, pp. 311-313+352, 2019.

[24] L. Wang, B. Hu, Y. Li, Y. Yao, and X. L. Chen, "A method of 3D geologic numerical modeling based on 3D mine-ANSYSflac3d," Low Temperature Architecture Technology, vol. 39, no. 8, pp. 83-85+102, 2017.

[25] Y. P. Li, X. L. Ding, and Z. Y. Wang, "Secondary development and application of visco-elastic constitutive model in FLAC3D software," Journal of Yangtze River Scientific Research Institute, vol. 2, pp. 10-13, 2014.

[26] Q. Zhang and Z. Liu, "Optimization of foundation pit excavation program based on FLAC3D," Subgrade Engineering, vol. 05, pp. 69-72, 2011.

[27] X. J. Yang, J. M. Wang, C. Zhu, M. He, and Y. Gao, "Effect of wetting and drying cycles on microstructure of rock based on SEM," Environmental Earth Sciences, vol. 78, no. 6, p. 183, 2018.

[28] L. Ban, C. Zhu, C. Qi, and Z. Tao, "New roughness parameters for 3D roughness of rock joints," Bulletin of Engineering Geology and the Environment, vol. 78, no. 6, pp. 4505-4517, 2019.

[29] A. L. Zhu, Y. Zhang, M. L. Miao, and J. Q. Xu, "Reinforcement mechanism of slopes with yielding anchor cables based on numerical simulation of FLAC3D," Chinese Journal of Geotechnical Engineering, vol. 39, no. 4, pp. 713-719, 2017.

[30] Y. T. Gao, S. Xiao, S. C. Wu, and Q. M. Tian, "Numerical simulation of the deformation and failure characteristics of consequent rock slopes and their stability," Chinese Journal of Engineering, vol. 37, no. 11, pp. 1403-1409, 2015.

[31] H. B. Wang, J. M. Li, Y. X. Jin, B. Zhou, and Y. Zhou, "The numerical methods for two key problems in rainfall-induced slope failure," Rock and Soil Mechanics, vol. 40, no. 2, pp. 777-784, 2019.

[32] R. J. Tan, M. S. Li, P. X. Xu, R. Hu, and Y. Su, "Numerical simulation of dynamic stability of slope rock mass under seismic loading," Chinese Journal of Rock Mechanics and Engineering, vol. 28, no. s2, pp. 3986-3992, 2009.

[33] C. Yang, Q. F. Qiao, and S. Lei, "Numerical simulation analysis of critical length of instable failure for bedding rock slope," Northwestern Geology, vol. 52, no. 4, pp. 250-262, 2019.

[34] Y. P. Liu, H. Deng, R. Q. Huang, J. L. Song, and J. K. Yuan, "Numerical simulation of seismic response of anti-dumping rock slope interbedded by hard and soft layers," Hydrogeology \& Engineering Geology, vol. 39, no. 3, pp. 30-37, 2012.

[35] Z. C. Chen, B. Yu, J. J. Hu, P. Wu, and L. Zheng, "Stability analysis of oversize open-pit slope based on numerical simulation using FLAC3D," Mining and Metallurgy, vol. 22, no. 3, pp. 1-6, 2013.

[36] W. Z. Gu, G. W. Li, G. J. He, J. B. Zhang, and R. Wang, "Anchorage scheme against imminent failure of slope based on 3-D numerical modeling back analysis," China Civil Engineering Journal, vol. 48, no. S2, pp. 202-207, 2015.

[37] W. D. Han, M. Y. Gu, X. Y. Yang, and X. Wang, "Slope stability based on FLAC3D numerical simulation," Journal of Liaoning Technical University, vol. 32, no. 9, pp. 1204-1208, 2013.
[38] Y. F. Duan, "Study on numerical simulation of mining induced secondary geological hazard assessment," Energy and Energy Conservation, vol. 8, pp. 37-42+44, 2021. 